\title{
Novel Biocomposites from Biobased Epoxy and Corn-Based Distillers Dried Grains (DDG)
}

\author{
Harekrishna Deka $^{1,2} \cdot$ Tao Wang ${ }^{1,2}$ - Amar K. Mohanty ${ }^{1,2} \cdot$ Manjusri Misra ${ }^{1,2}$
}

Published online: 12 September 2015

(C) The Author(s) 2015. This article is published with open access at Springerlink.com

\begin{abstract}
The growing ethanol production around the world demands more value-added applications for its main byproduct, distillers grains. The present work reports the study of using corn based distillers dried grains (DDG) as biofillers for biobased epoxy resin and the mechanical, physical and thermal properties of the composites. The biobased epoxy resin is the blend of diglycidylether of bisphenol-A based resin and epoxidized soybean oil. The incorporation of DDG into the biobased resin accelerated the curing process as evident from the differential scanning calorimetry and temperature-modulated Fourier transform infrared spectroscopy. The $40 \mathrm{wt} \%$ DDG filled composite showed an excellent retention of flexural strength of up to $94 \%$ of that of the neat epoxy. Furthermore, the composite filled with the DDG treated with epoxy functionalized oligomeric silsesquioxane showed even better flexural properties thanks to the improved wettability of the biobased resin with the filler. Dynamic mechanical analysis showed a $12 \%$ increment in storage modulus for the surface-treated DDG composites over the biobased resin. The improved interfacial adhesion between the DDG and matrix through the surface modification was also observed in the morphological characterization with electron microscope. The study demonstrates the viability of
\end{abstract}

Amar K. Mohanty

mohanty@uoguelph.ca

$\triangle$ Manjusri Misra

mmisra@uoguelph.ca

1 Department of Plant Agriculture, Bioproducts Discovery and Development Center (BDDC), University of Guelph, Guelph, ON N1G 2W1, Canada

2 School of Engineering, University of Guelph, Thornbrough Building, Guelph, ON N1G 2W1, Canada combining DDG biofiller with the epoxy bioresin to produce novel biomaterials at low cost.

Keywords Renewable resource - Epoxy resin . Epoxidized soybean oil · Distillers dried grains . Flexural property

$\begin{array}{ll}\text { Abbreviations } \\ \text { DDG } & \text { Distillers dried grains } \\ \text { DGEBA } & \text { Diglycidylether of bisphenol-A } \\ \text { ESO } & \text { Epoxidized soybean oil } \\ \text { DSC } & \text { Differential scanning calorimetry } \\ \text { FTIR } & \text { Fourier transform infrared spectroscopy } \\ \text { DDGS } & \text { Distillers dried grains with soluble } \\ \text { DWG } & \text { Distillers wet grains } \\ \text { MDI } & \text { Methylenediphenyl diisocyanate } \\ \text { POSS } & \text { Glycidyl polyhedral oligomeric } \\ & \text { silsesquioxane } \\ \text { SEM } & \text { Scanning electron microscope } \\ \text { BE/DDG } & \text { Biobased epoxy/distillers dried grains } \\ \text { BE/MDDG } & \text { Biobased epoxy/modified distillers dried } \\ & \text { grains }\end{array}$

\section{Introduction}

The limited fossil reserves have compelled the industrial and scientific communities to explore using renewable resources to reduce our dependence on petroleum. The production of corn-based bioethanol as a renewable fuel is growing rapidly throughout the world. In 2014 alone, the worldwide production of ethanol was about 25 billion gallons, of which over 14 billion gallons were produced by 
The United States, the world's largest producer [1]. In North America, the vast majority of ethanol is produced from corn. Two different methods are used to produce ethanol from corn, namely dry milling and wet milling [2]. The dry milling process is simpler than the wet milling process and consequently more commonly used [3]. The dry milling process produces a large amount of distillers grains as co-product. The distillers grains can be in the form of dried distillers grains with solubles (DDGS) or dried distillers grains (DDG) depending on whether the solubles, mostly simple sugar, have been removed. According to stoichiometry, $1 \mathrm{~kg}$ of corn produces $1 / 3 \mathrm{~kg}$ of each of ethanol, distillers grains and carbon dioxide [4]. At present, DDGS is mainly used as livestock feed due to its high protein content. However, it is reported that the DDGS production has already exceeded the consumption rate of animal feed [5]. In North America, the DDGS production has increased by $260 \%$ from 2005 to 2010 [6]. The excess DDGS has also become a threat to the environment [2]. Consequently, new alternative pathways for the utilization of the bioethanol coproducts are in demand. Several attempts have been made to find value-added applications of DDGS including extraction of protein and cellulose from DDGS $[7,8]$ and using DDGS as biofiller for resins [3, 4], thermoplastics [5, 9, 10], and biocomposites $[2,11]$.

Petroleum-derived epoxy resins are commonly used for the preparation of high-performance composites due to their excellent mechanical strength and stiffness, exceptional solvent resistance, and easy processing $[12,13]$. The main drawbacks of epoxy are their brittleness and high cost. In this regard, the incorporation of the flexible, reactive epoxidized vegetable oil (ESO) can act as a toughening agent promoting flexibility to the resultant material [14]. The vegetable epoxidized oils which are commercially available have applications in coatings and plasticizers. Greater economic return to the farmers can be achieved by value-added applications of such epoxidized vegetable oils. The biobased resin used in this study contains $30 \%$ ESO. Furthermore, we explore the feasibility of adding DDGS as a filler to the biobased resin to reduce the cost of the final product while maintaining its mechanical and thermal properties.

DDGS contains $27 \%$ protein, $13 \%$ oils, and $56 \%$ other components including fibers [15]. It is available in large quantities and contains a high amount of hydrophobic components [16]. The presence of different functionalities such as hydroxyl and amine groups provides a wide window for a variety of chemical linkages to polymers. The utilization of the methylenediphenyl diisocyanate (MDI) as a compatibilizer to react with the hydroxyl group of DDGS has been shown in the literature $[5,9]$. It is expected that the hydroxyl groups of the DDGS will take part in the curing process, leading to improved compatibility and interfacial adhesion.

Herein, the authors wish to report for the first time, to the best of our knowledge, the utilization of the industrial co-product DDGS as a biofiller for biobased epoxy resin. A previous study published by our group has shown that washing the DDGS with water removes the solubles and improves the thermal stability of the material [17]. Therefore, the DDGS used in this work is washed with water and is henceforward referred to as DDG. The influence of the DDG biofiller on the curing process was evaluated with the help of differential scanning calorimetry and temperature-modulated Fourier transform infrared spectroscopy. The mechanical, thermal and dynamic mechanical properties of the composites were investigated. In addition, in order to enhance the adhesion between the filler and the epoxy matrix, the DDG was treated with epoxy functionalized polyhedral oligomeric silsesquioxanes (POSS). The modification is expected to introduce epoxy ring with oligomeric structure onto the surface of the DDG, therefore providing more wettability of the resin to the filler. The effect of the treatment on the properties of the composite was investigated. The morphology of the composites was characterized by scanning electron microscopy.

\section{Materials and Methods}

\section{Materials}

The main component of the biobased epoxy resin was diglycidylether of bisphenol-A (DGEBA) based epoxy resin, PT2712A, produced by PTM\&W Industries Inc. and provided by Composites Canada. Its epoxy equivalent weight is 186.7 and it has a viscosity of $1000 \mathrm{cP}$ and a specific gravity of $1.08 \mathrm{~g} / \mathrm{cc}$. In the biobased epoxy formulation, $30 \mathrm{wt} \%$ of DGEBA was replaced with the same weight of epoxidized soybean oil (ESO). ESO was supplied by Arkema, USA under the trade name of Vikoflex 7170. Its epoxy equivalent weight is 226 and it has a molecular weight of 1000 and a viscosity of $420 \mathrm{cP}$ at $25^{\circ} \mathrm{C}$. The biobased epoxy resin was cured by Lindride $6 \mathrm{k}$ curing agent. It is a mixture of isomeric forms of methyl tetrahydrophthalic anhydride which has been pre-catalyzed with quaternary amine. The curing agent was kindly supplied by Lindau Chemicals Inc., USA. Lindride $6 \mathrm{k}$ has a viscosity of $75-200 \mathrm{cps}$ at $25^{\circ} \mathrm{C}$ and an anhydride equivalent weight of 165-175. The DDGS was kindly supplied by GreenField Ethanol Inc., Chatham, Canada. Glycidyl polyhedral oligomeric silsesquioxane (POSS) Cage Mixture, EP0409, was used to modify the DDG surface. It was supplied by Hybrid Plastics, USA. It is an epoxy functionalized material having the chemical formula of 
$\left(\mathrm{C}_{6} \mathrm{H}_{11} \mathrm{O}_{2}\right)_{\mathrm{n}}\left(\mathrm{SiO}_{1.5}\right)_{\mathrm{n}} ; \mathrm{n}=8,10$, or 12 . It has a molecular weight of 1338-2007, an epoxy equivalent weight of 167, a density of $1.25 \mathrm{~g} / \mathrm{mL}$, and a viscosity of $4800 \mathrm{cP}$ at $25^{\circ} \mathrm{C}$. The structures of some of the chemicals used in the study are presented in Fig. 1.

\section{Preparation of the Composites}

The DDG was obtained by washing the as-received DDGS with water and dried according to a procedure published previously [17]. In order to achieve better dispersion, the DDG was ground into powder with a kitchen blender. The composites were prepared by mixing the DDG with biobased epoxy resin under high mechanical shearing followed by compression molding. Before fabrication of the composites, the bioresin and DDG were dried in a vacuum oven at $50-55^{\circ} \mathrm{C}$ for $2-3 \mathrm{~h}$. They were then mixed with a mechanical stirrer at $400 \mathrm{rpm}$ for half an hour. The DDG/ resin mixture was poured into a mold to cure in compression molding at $80{ }^{\circ} \mathrm{C}$ for $4 \mathrm{~h}$ followed by post curing at $110{ }^{\circ} \mathrm{C}$ for $1 \mathrm{~h}$. The effect of two different curing pressures, 1000 and $2000 \mathrm{psi}$, was also studied. The composites were denoted as BE/DDG0, BE/DDG30, BE/DDG40, and
BE/DDG50 corresponding to DDG contents of $0,30,40$ and $50 \mathrm{wt} \%$, respectively. Although the composites with lower filler concentrations such as 10 and $20 \mathrm{wt} \%$ were also tried, it was very difficult to get the filler mixed well with the matrix when the filler content was too low and inconsistent test results were obtained. Therefore these data were not reported.

The modification of the DDG particles was carried out by treating them with the epoxy terminated POSS to improve the compatibilization between DDG and the biobased resin. DDG was mixed thoroughly with the epoxidized POSS and Lindride $6 \mathrm{k}$ and kept at $80{ }^{\circ} \mathrm{C}$ for half an hour in an oven. The amount of POSS used for treating the DDG was kept at 5 parts per hundred of the total weight of DGEBA and ESO in the final composite and the amount of Lindride $6 \mathrm{k}$ used was calculated based on its equivalent weight. The mixing time was chosen based on a study using temperature modulated FTIR (Fig. 2). It was observed that after half an hour the absorbance of the epoxy ring became almost constant. It is expected that the remaining unreacted epoxy groups on the DDG surface will mix with the bulk epoxy in the matrix resulting in more effective compatibilization. The composite filled with

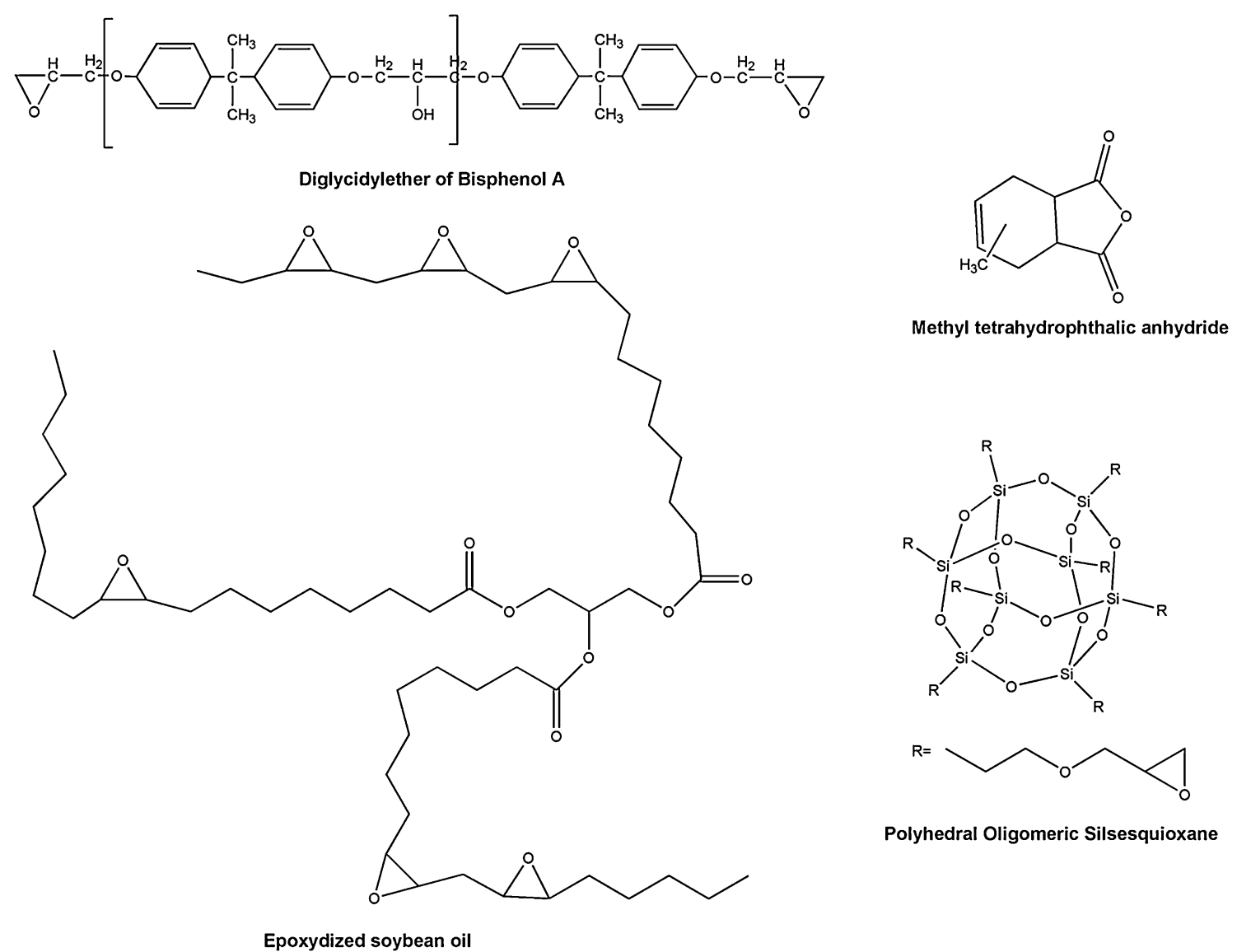

Fig. 1 Molecular structure of the epoxy resin, curing agent, ESO and POSS 


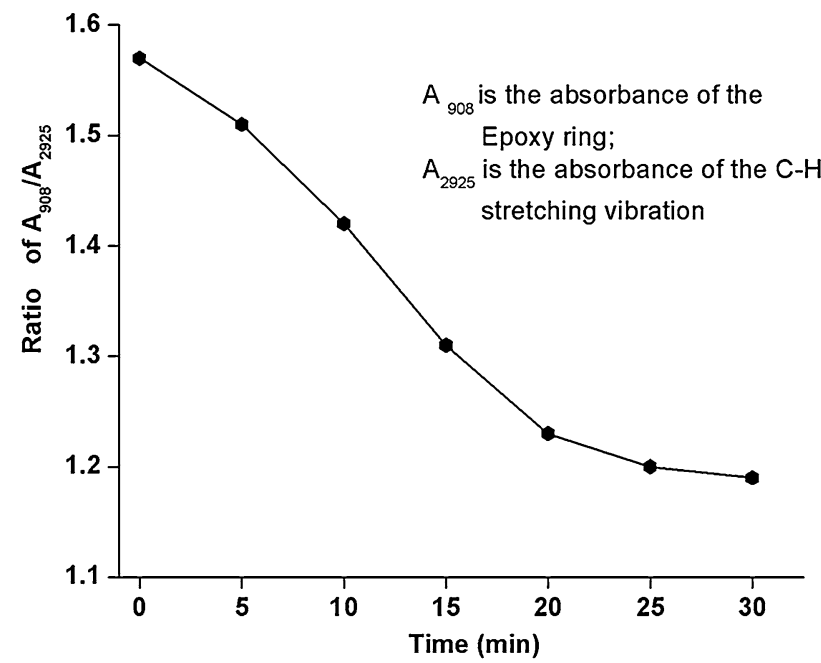

Fig. 2 Absorbance ratio of $\mathrm{A}_{908} / \mathrm{A}_{2925}$ at isothermal heating $\left(80^{\circ} \mathrm{C}\right)$

$40 \mathrm{wt} \%$ surface-modified DDG was prepared in the same method as explained in the previous section and denoted as BE/MDDG40.

\section{Characterization Techniques}

\section{Fourier Transform Infrared Spectroscopy (FTIR)}

The FTIR spectra of the samples were recorded using a

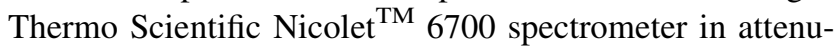
ated total reflection (ATR) mode. The spectra were the average of 64 scans at a resolution of $4 \mathrm{~cm}^{-1}$. The curing study was carried out by recording the spectra changes while heating the samples from room temperature to $180{ }^{\circ} \mathrm{C}$ at a rate of $10{ }^{\circ} \mathrm{C} / \mathrm{min}$ using a GladiATR accessory on the spectrometer.

\section{Dynamic Mechanical Analyzer (DMA)}

The dynamic mechanical properties were obtained using a TA instruments DMA Q800. All the experiments were done using a dual cantilever clamp, from -50 to $180{ }^{\circ} \mathrm{C}$ at a heating rate of $3{ }^{\circ} \mathrm{C} / \mathrm{min}$, with $15 \mu \mathrm{m}$ oscillating amplitude and $1 \mathrm{~Hz}$ frequency.

\section{Thermogravimetric Analysis (TGA)}

The thermostability of the samples was characterized using a TA instruments TGA Q500. The samples were heated from room temperature $\left(25^{\circ} \mathrm{C}\right)$ to $800{ }^{\circ} \mathrm{C}$ at a ramp rate of $10{ }^{\circ} \mathrm{C} / \mathrm{min}$ under nitrogen purge. The thermal and dynamic mechanical properties reported here are the averages of at least three measurements.

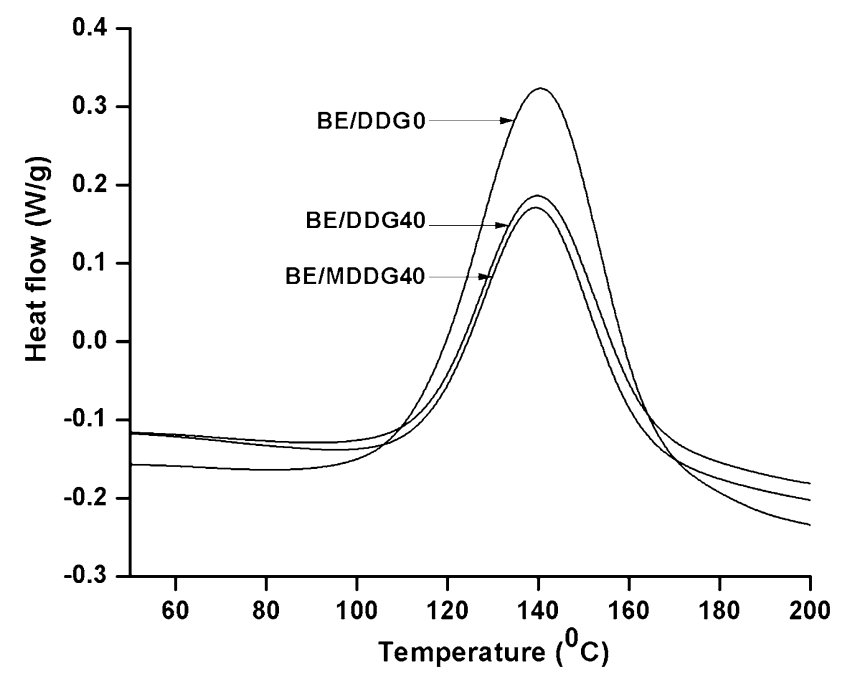

Fig. 3 DSC thermograms of the neat biobased epoxy and the composites

\section{Differential Scanning Calorimetry (DSC)}

The heat flow during the curing of the resin and composites was recorded using a TA Instruments DSC Q 200. About $10 \mathrm{mg}$ sample was heated in a sealed aluminum pan from -50 to $150{ }^{\circ} \mathrm{C}$ at a ramp rate of $10{ }^{\circ} \mathrm{C} / \mathrm{min}$, under a nitrogen flow of $50 \mathrm{~mL} / \mathrm{min}$.

\section{Scanning Electron Microscope (SEM)}

The impact fracture surface of the composites was observed using a scanning electron microscope (SEM), Inspect S50, at an accelerating voltage of $10 \mathrm{kV}$ after gold sputtering.

\section{Flexural Properties}

The flexural properties of the neat epoxy and the composites were measured using a Universal Testing Machine, Instron 3382. The flexural properties were measured according to ASTM D790 at a cross head speed of $1.89 \mathrm{~mm} / \mathrm{min}$. All data reported are the average of at least five measurements.

\section{Density Measurement}

The density of the neat epoxy and the composites was measured by using Alfa Mirage MD-300S electronic densimeter, which follows the Archimedes principle. 
Initiation:

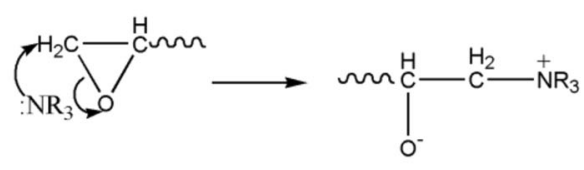

Propagation:

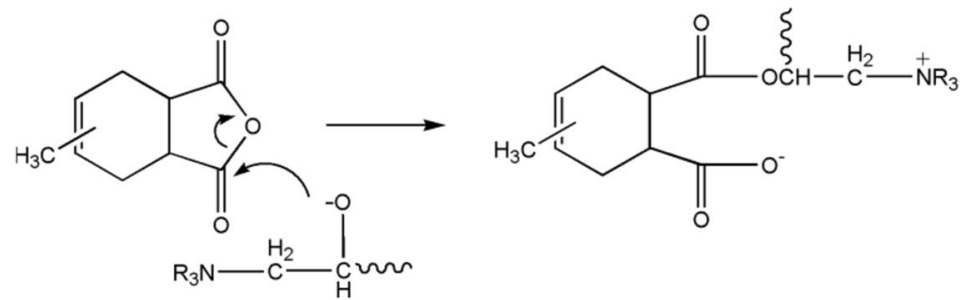

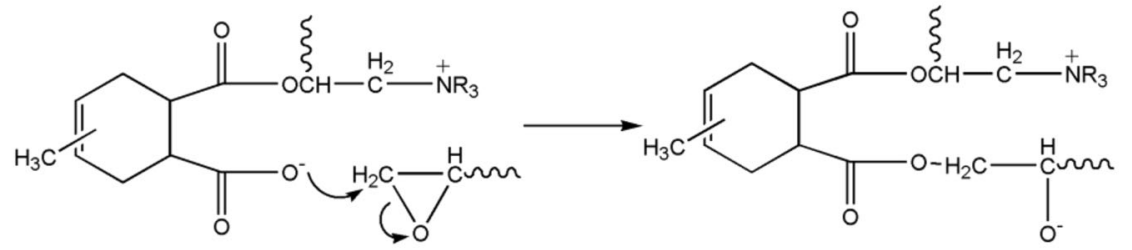

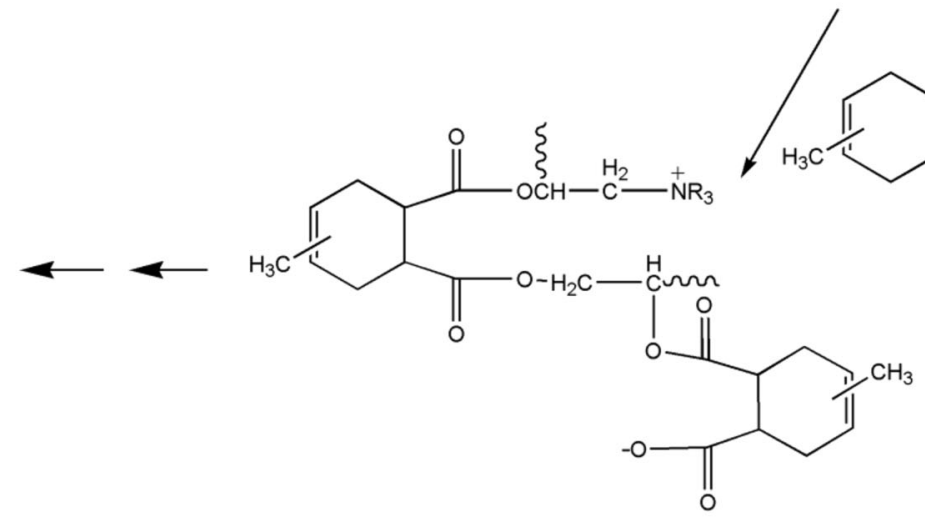

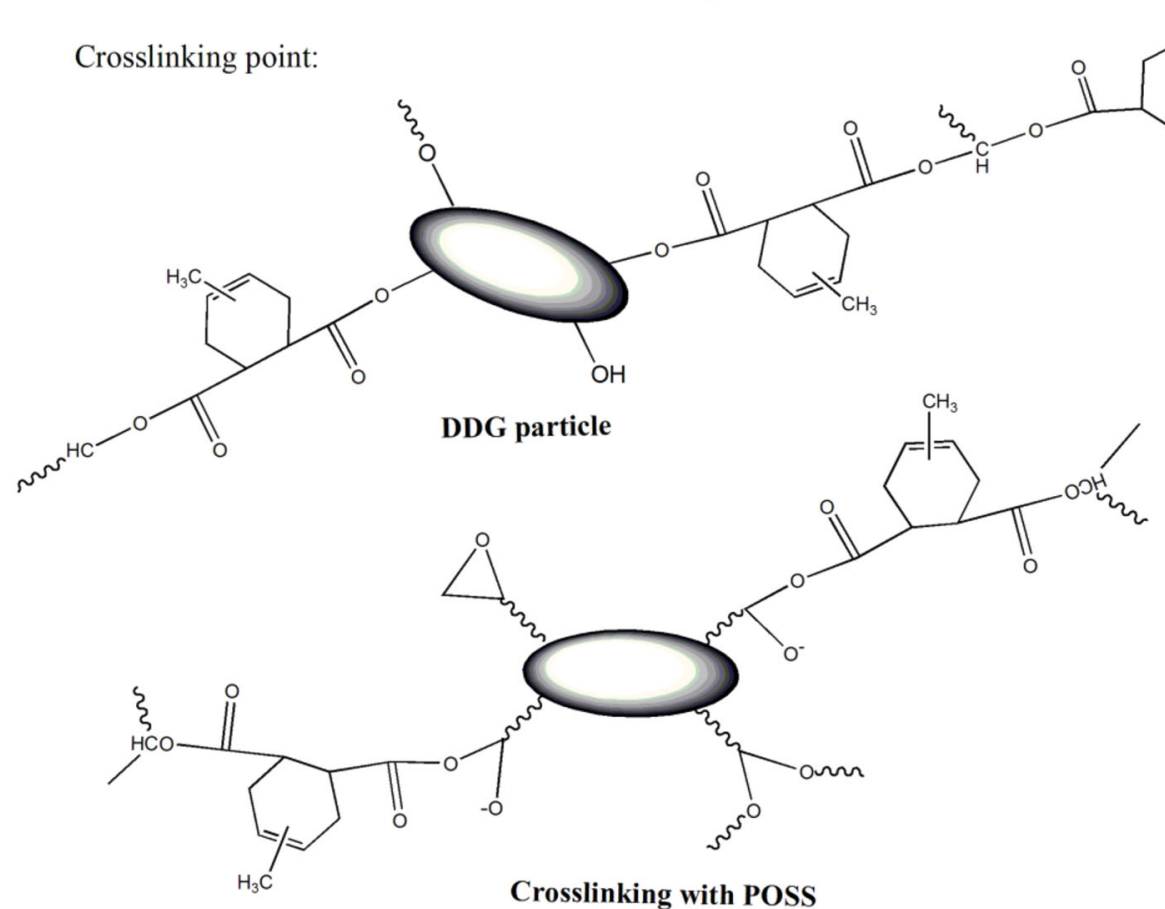

Fig. 4 Proposed mechanisms of the curing of the biobased epoxy resin and the crosslinking of DDG with POSS 


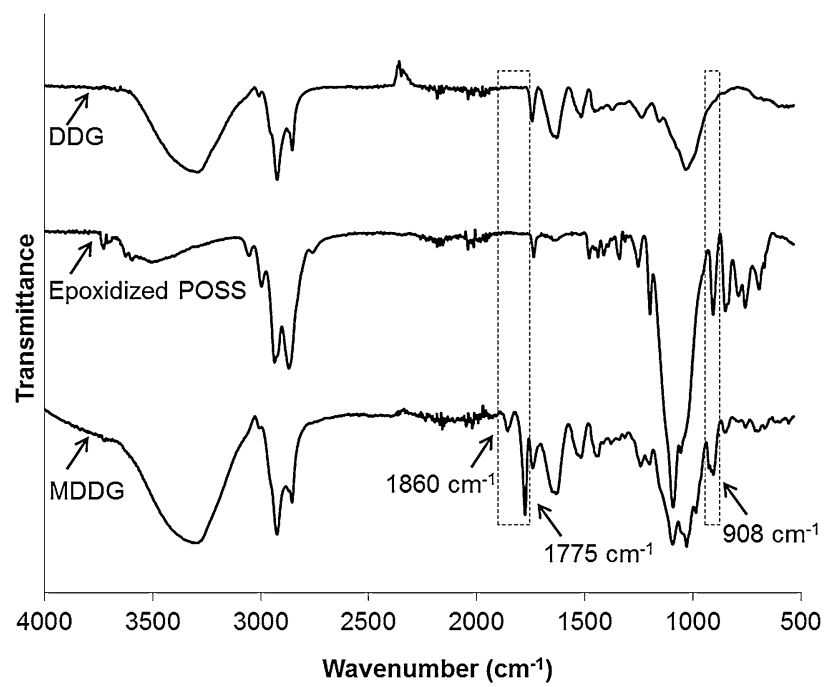

Fig. 5 Comparison of the FTIR spectra of DDG, epoxidized POSS, and MDDG

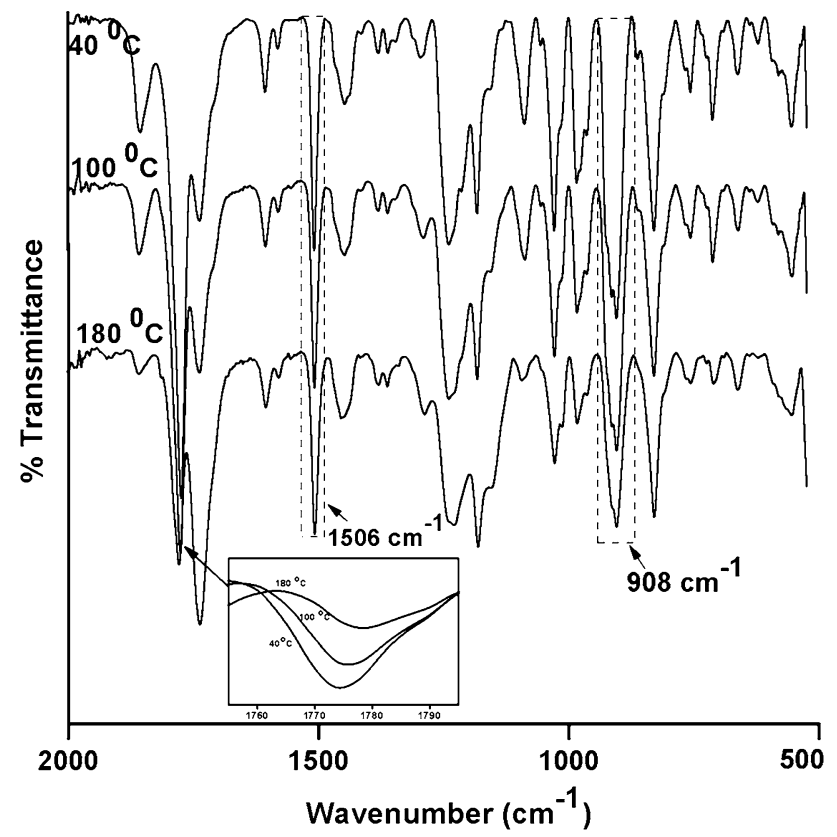

Fig. 6 Representative FTIR spectra of the mixture of the biobased epoxy and anhydride curing agent during dynamic heating from room temperature to $180{ }^{\circ} \mathrm{C}$. Inset is the close-up view of the area around $1770 \mathrm{~cm}^{-1}$

\section{Results and Discussion}

In the present work, composites containing biobased epoxy as the matrix and 30,40 and 50\% DDG as fillers were prepared. The effect of the addition of the DDG and the effect of the surface treatment of the DDG on the properties of the composites were studied.
Effect of DDG on Curing Behavior of the Biobased Resin

The effect of DDG incorporation on the curing behavior of the biobased epoxy resin is first analyzed by measuring the heat flow using the DSC (Fig. 3). The biobased epoxy with the anhydride curing agent showed a curing peak temperature at $140{ }^{\circ} \mathrm{C}$, while the curing peak for BE-DDG40 and BE-MDDG40 was at $136{ }^{\circ} \mathrm{C}$. In addition, the composites showed decreased peak height as compared to the neat epoxy. This indicates the ease of curing for the composites [18]. A mechanism proposed to explain the aforementioned observation is shown in Fig. 4. The epoxy resin is cured by the reaction between the epoxy rings and the cyclic anhydrides at elevated temperatures. The propagation of crosslinking takes place through anionic copolymerization [18]. However, steric hindrance slows down the curing process over time [19]. In the case of the composites, DDG and POSS-modified DDG particles in the matrix provide crosslinking points, facilitating the curing process as shown in the proposed scheme in Fig. 4.

The change in the surface properties of DDG induced by POSS treatment was characterized by FTIR spectroscopy. A comparison of the spectra of the DDG, epoxidized POSS, and the MDDG is shown in Fig. 5. The epoxidized POSS shows the characteristic absorption band of epoxy at $908 \mathrm{~cm}^{-1}$, which is attributed to the $\mathrm{C}-\mathrm{O}-\mathrm{C}$ bending vibration [20]. The appearing of this peak in the DDG after the treatment shows that the surface of the DDG has been coated with the POSS and not all the epoxy groups of the POSS have been cured. Furthermore, the spectrum of the MDDG shows two carbonyl absorption bands at 1860 and $1775 \mathrm{~cm}^{-1}$, which are not observed on the spectra of the DDG and POSS. These bands are characteristic of cyclic anhydride, therefore indicating the presence of the anhydride curing agent Lindride $6 \mathrm{k}$. These evidences show that the 30 min curing did not fully cure the epoxy functionality on the DDG surface. The remaining epoxy groups are available for interaction with the matrix when the MDDG was used as filler in the composites.

The curing behavior of the resin and the composites was then studied by using FTIR (Figs. 6, 7) and the characteristic bands are tabulated in Table 1. The samples were heated from room temperature to $180{ }^{\circ} \mathrm{C}$ with the same heating rate as used in the DSC study, $10{ }^{\circ} \mathrm{C} / \mathrm{min}$. The study shows the epoxy conversion with respect to temperature. The characteristic epoxy band at $908 \mathrm{~cm}^{-1}$ was compared with the aromatic $\mathrm{C}=\mathrm{C}$ stretching vibration at $1506 \mathrm{~cm}^{-1}$, an internal standard which remains unchanged throughout the reaction. The quantification of epoxy fractional conversion is estimated using the following equation, 

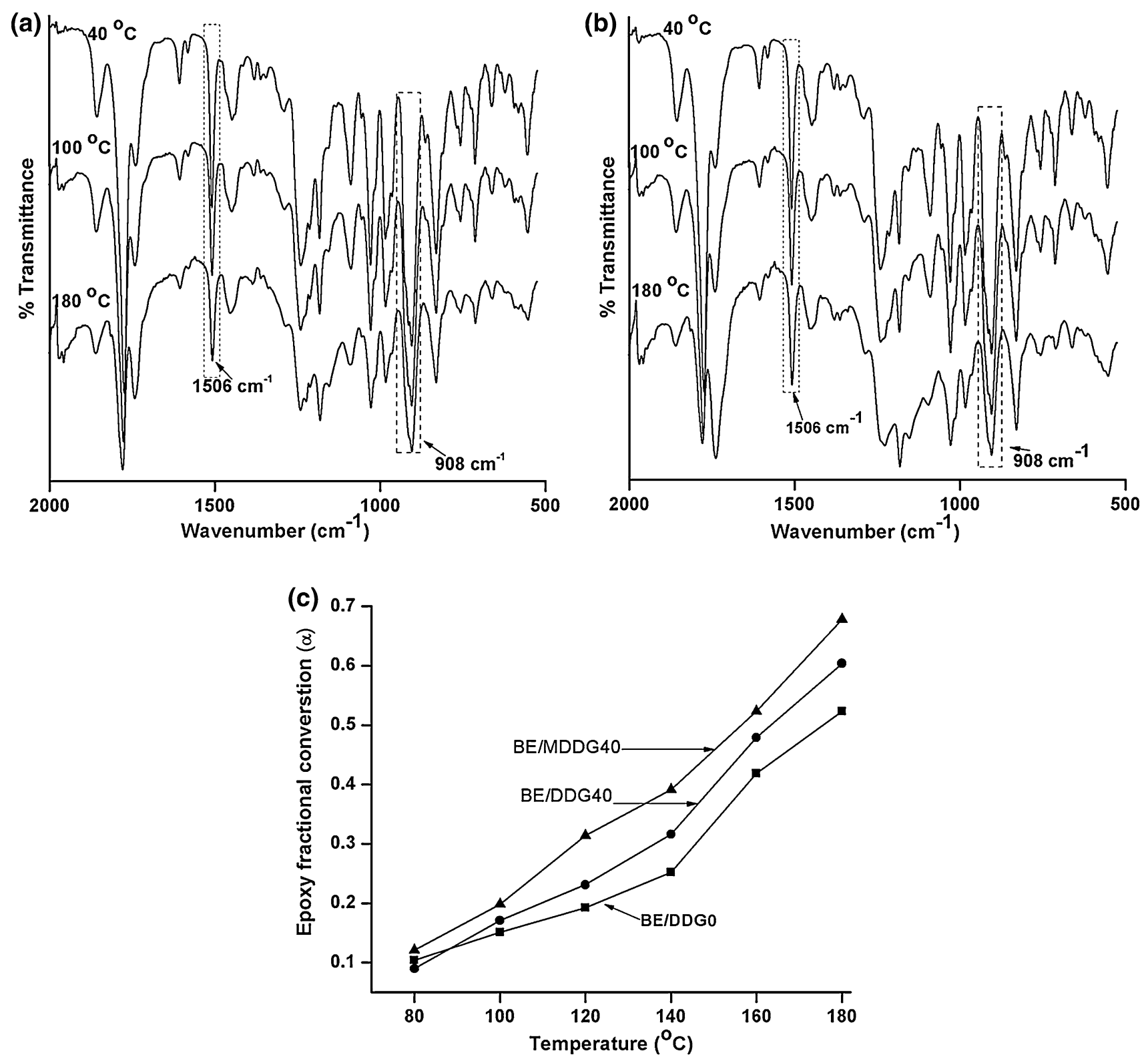

Fig. 7 Representative FTIR spectra of a BE/DDG40 and b BE/ MDDG40 mixed with the anhydride curing agent during dynamic heating from room temperature to $180{ }^{\circ} \mathrm{C}$. c Comparison of the epoxy

$\alpha=1-\frac{\left(\mathrm{A}_{\text {epoxy }}-\mathrm{A}_{\text {aromatic }}\right)_{\mathrm{t}}}{\left(\mathrm{A}_{\text {epoxy }}-\mathrm{A}_{\text {aromatic }}\right)_{\mathrm{t}=0}}$,

where $\mathrm{A}_{\text {epoxy }}$ and $\mathrm{A}_{\text {aromatic }}$ are the areas under the absorption peaks of the epoxy group at $908 \mathrm{~cm}^{-1}$ and the aromatic $\mathrm{C}=\mathrm{C}$ stretching vibration at $1506 \mathrm{~cm}^{-1}$, respectively.

From Fig. 6, it is observed that with the increase of temperature, the intensities of the epoxy band at $908 \mathrm{~cm}^{-1}$ and anhydride bands at 1860 and $1775 \mathrm{~cm}^{-1}$ (with the latter shown clearly in the inset) decrease continuously. This shows the consumption of the epoxy and anhydride groups during the curing process. The increase of the fractional conversion $(\alpha)$ of the bioresin and the BE/DDG40 and BE/ MDDG40 composites

intensity of the ester band at $1727 \mathrm{~cm}^{-1}$ reflects the formation of the ester bond [21]. The peak at $\sim 1230 \mathrm{~cm}^{-1}$ corresponds to the overlapping zone of the epoxy vibration ring and $\mathrm{C}-\mathrm{O}$ stretching vibration of the anhydride and $\mathrm{C}-$ $\mathrm{O}$ stretching vibration of the ester. The decreased intensity of this peak is also due to the consumption of the epoxy and anhydride groups. Similar behavior is observed in the DDG and MDDG filled composites as shown in Fig. 7a, b. Figure $7 \mathrm{c}$ shows the epoxy fractional conversion versus temperature. The epoxy conversion rate of the DDG filled composites is higher than that of the neat epoxy resin at temperatures above $100{ }^{\circ} \mathrm{C}$. This observation corroborates 
Table 1 Attribution of the FTIR absorption bands

\begin{tabular}{ll}
\hline Wavenumber $\left(\mathrm{cm}^{-1}\right)$ & Assignment \\
\hline $\begin{array}{l}\text { Biobased epoxy } \\
3050\end{array}$ & Aromatic $-\mathrm{C}-\mathrm{H}$ stretching vibration \\
$2966,2930,2868$ & Aliphatic $-\mathrm{C}-\mathrm{H}$ stretching vibration \\
$1608,1579,1510$ & Stretching vibration of $-\mathrm{C}-\mathrm{C}$ of the 1,4-substituted benzene ring \\
1230,1182 & $-\mathrm{C}-\mathrm{H}$ benzenic band \\
1130 & $-\mathrm{C}-\mathrm{O}$ of the epoxy ring \\
1101 & $-\mathrm{C}-\mathrm{H}$ benzenic \\
1035 & Symmetric aromatic ether stretching vibration and $-\mathrm{C}-\mathrm{H}$ of the \\
& $1,4-$ substituted benzene \\
908 & Characteristic vibration band (symmetric) of the epoxy ring \\
830 & $-\mathrm{CH}$ band of the epoxy group in biobased epoxy resin \\
$D D G$ & \\
$3645-3035$ & Overlapping bands of O-H and N-H stretching vibrations \\
2925,2850 & $-\mathrm{C}-\mathrm{H}$ symmetric asymmetric and stretching vibrations \\
1735 & $-\mathrm{C}=\mathrm{O}$ band \\
1634 & Amide I band \\
1524 & Amide II band of C-N and N-H groups \\
$1500-1200$ & $\mathrm{C}-\mathrm{H}$ and O-H bending, C-C and C-O skeletal vibrations \\
1104 & $\mathrm{C}-\mathrm{O}$ vibration band \\
1030 & $\mathrm{C}-6$ skeletal vibration band \\
\hline
\end{tabular}

Table 2 The flexural properties of the pristine biobased resin and green composites

\begin{tabular}{lcl}
\hline Sample code & Flexural strength $(\mathrm{MPa})$ & Flexural modulus $(\mathrm{GPa})$ \\
\hline $\mathrm{BE}$ & $99 \pm 0.5$ & $2.8 \pm 0.01$ \\
$\mathrm{BE} / \mathrm{DDG} 30$ & $59 \pm 3.0$ & $2.9 \pm 0.02$ \\
$\mathrm{BE} / \mathrm{DDG} 40$ & $86 \pm 1.4$ & $2.8 \pm 0.05$ \\
$\mathrm{BE} / \mathrm{DDG} 50$ & $56 \pm 2.1$ & $2.7 \pm 0.07$ \\
$\mathrm{BE} / \mathrm{MDDG} 40$ & $101 \pm 4.1$ & $3.2 \pm 0.03$ \\
\hline
\end{tabular}

the result of the DSC analysis indicating that the addition of DDG and MDDG particles facilitates the curing process, with the DDG and MDDG acting as the crosslinking sites. This effect is more pronounced in the case of MDDG.

\section{Mechanical Properties of the Composites}

Density is an important parameter for polymer composites especially when specific strength or modulus is concerned. The density of DDGS has been reported to be $1.29 \mathrm{~g} / \mathrm{cc}$ [22]. The densities of the neat epoxy and the composites filled with 30, 40, and $50 \mathrm{wt} \%$ DDG were measured to be $1.180,1.201,1.204$, and $1.208 \mathrm{~g} / \mathrm{cc}$, respectively. The addition of DDG led to only a slight increase in the density of the epoxy.
Improvement of the material's strength and stiffness is desired when adding filler to the material. However, when improvement is not possible, the addition of the filler should maintain the material's properties [23]. In the current work, the composites were prepared by compression molding which causes less damage to the biofillers as compared to other common processes such as injection molding and extrusion [3]. The flexural properties including strength and modulus are tabulated in Table 2. The neat epoxy shows flexural strength of $99 \mathrm{MPa}$ and flexural modulus of $2.8 \mathrm{GPa}$. The DDG filled composites showed the same modulus, but lower strength compared with the neat epoxy. This decrease in the strength is expected with the addition of the rigid DDG particles. The $40 \%$ DDG filled composite, BE/DDG40, showed the highest strength among the three composites. The composite filled with $30 \%$ DDG was found in the morphological study shown later to contain many defects. This might be caused by insufficient packing of the particles in the matrix. These defect contributed to the early failure of the composite during flexural testing, resulting in low strength. In the case of BE/DDG50, because the filler content is very high, the amount of resin may not be enough to act as a continuous matrix phase, also leading to low strength. The filler content of $40 \%$ is chosen for the study of the effect of surface treatment of the DDG.

One of the greatest challenges in utilizing biological materials for composites is to ensure good compatibilization 

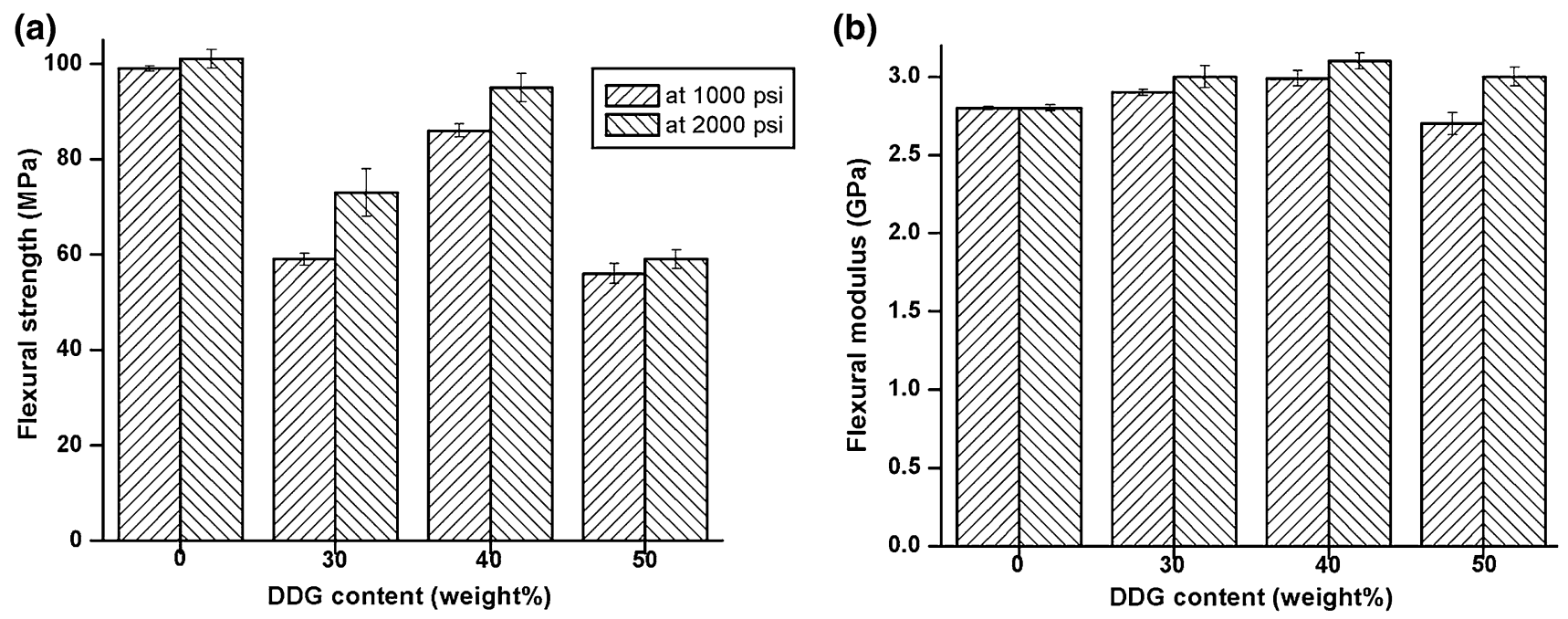

Fig. 8 Comparison of the flexural a strength and $\mathbf{b}$ modulus at different compression pressures of the neat epoxy resin and the composites
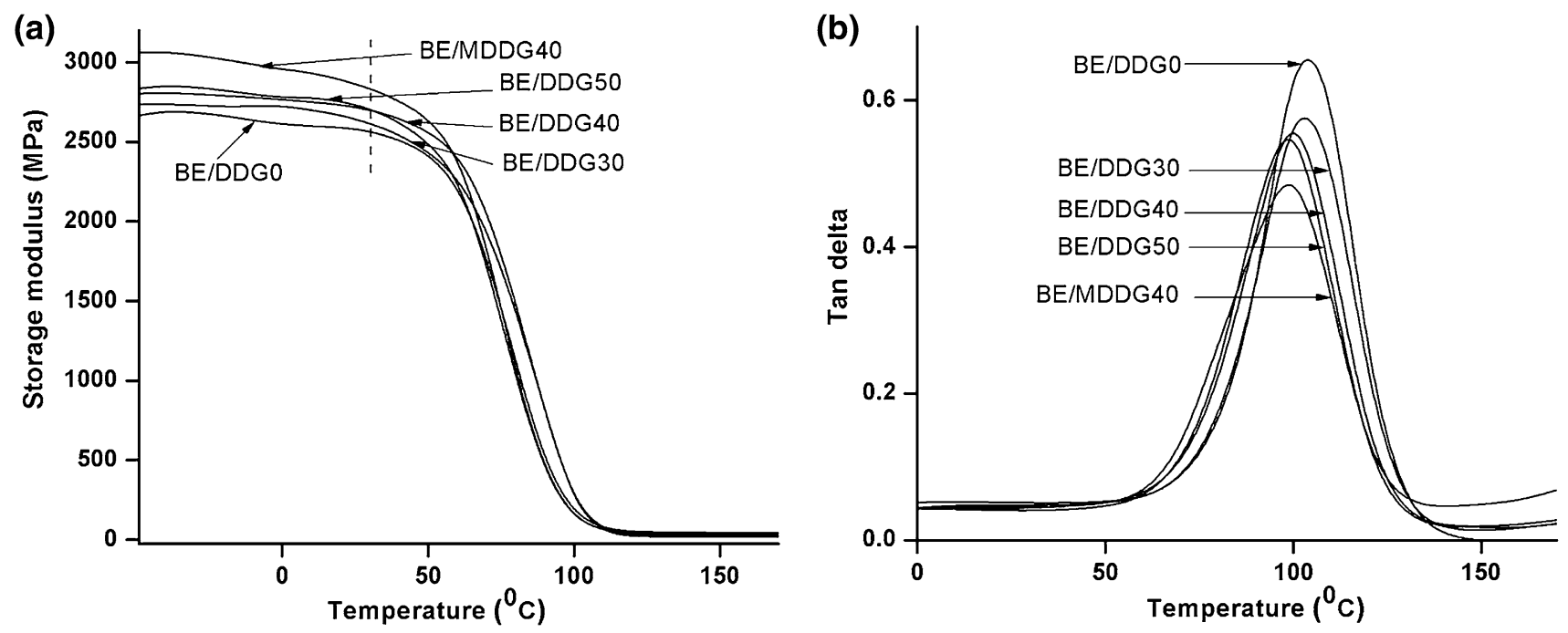

Fig. 9 Temperature dependence of a the storage modulus and $\mathbf{b}$ tan delta of the neat resin and the composites

between the filler and matrix [24]. In the current work, modifying the DDG particles with epoxy-functionalized POSS resulted in enhanced interfacial adhesion between the filler and the matrix. The flexural modulus of the $40 \%$ MDDG filled composite was higher than that of the neat epoxy and the strength of the composite was the same as that of the neat epoxy.

It has been reported by Pfister and Larock [25] that the mechanical properties of resin composites can be improved by increasing mold pressure when curing is carried out by compression molding. Therefore we prepared DDG filled epoxy composites at different compression pressures. Figure 8 compares the flexural strength and modulus of the samples obtained by curing under 1000 and 2000 psi, respectively. An improvement of $24 \%$ in strength was achieved for the $30 \mathrm{wt} \%$ DDG composite by increasing the compression pressure from 1000 psi to 2000 psi. The strength of the $40 \mathrm{wt} \%$ DDG composite was $94 \%$ of that of the neat polymer. This may be attributed to enhanced filler-matrix interaction at higher compression pressures, which enhances packing and minimizes the occurrence of voids. Voids and porosity generally act as stress concentrators leading to reduction in mechanical strength [25].

\section{Dynamic Mechanical Analysis}

The dynamic mechanical properties including the storage modulus and tan delta of the composites are shown in Fig. 9. The storage modulus of the composites represents the stored energy in the materials due to their viscoelastic 

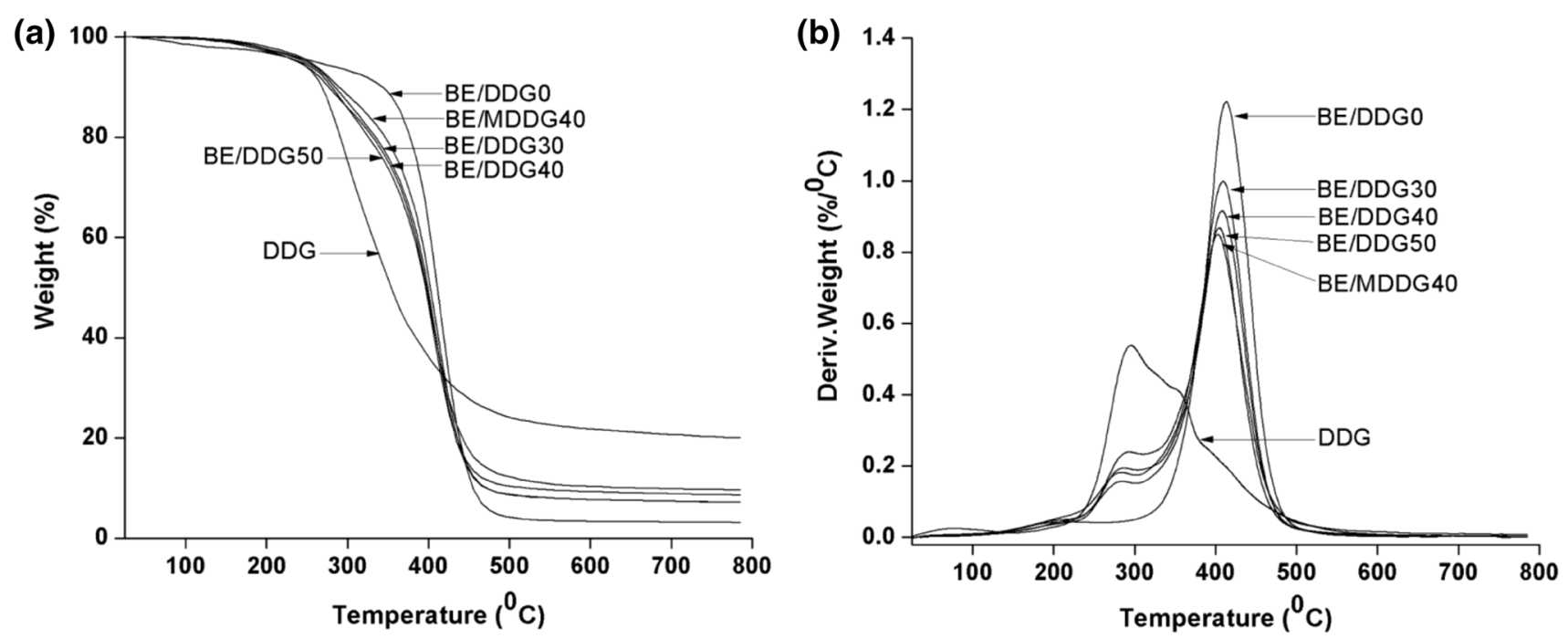

Fig. 10 The a thermogravimetric and $\mathbf{b}$ derivative thermogravimetric curves of the neat resin and the composites

nature. The DDG composites showed a small increment in storage modulus and it is well in agreement with the flexural modulus data. The $40 \mathrm{wt} \%$ DDG composite showed an $8 \%$ increment and the 40 wt $\%$ MDDG composite showed a $12 \%$ increment over the neat polymer at room temperature. This is due to the enhanced interaction between the surface modified DDG and the biobased resin. $\mathrm{Li}$ and Sun [5] have also reported enhanced storage modulus for DDGS filled poly(lactic acid) (PLA) biocomposites by using methylene diphenyl diisocyanate (MDI) as a coupling agent to link DDGS particles with the polymer through chemical linkages such as urethane bond. With the increase of temperature, the storage modulus of the neat polymer and the composites decreased. This is due to the increased chain mobility of the polymers at higher temperatures [26].

Figure $9 \mathrm{~b}$ shows the $\tan \delta$ versus temperature curves for the composites. It reveals the molecular transition of the materials. The peak of the $\tan \delta$ curve is often interpreted as the glass transition temperature $\left(\mathrm{T}_{\mathrm{g}}\right)$. It is observed that the $\mathrm{T}_{\mathrm{g}}$ shifted by $5{ }^{\circ} \mathrm{C}$ towards lower temperatures for the composites compared to the neat polymer and the composites showed reduced $\tan \delta$ intensity.

\section{Thermal Properties}

The thermal stability of the composites and the DDG (TGA and DTA curves) is shown in Fig. 10. DDG shows a broad decomposition range (from 230 to $480{ }^{\circ} \mathrm{C}$ ), which can be explained by the fact that DDG contains multiple compositions such as protein, carbohydrate, and fat, etc. [5]. All the composites showed a lower decomposition temperature than the bioepoxy resin. This is due to the lower thermal stability of the DDG particles than the epoxy. The BE/DDG0 had a $\mathrm{T}_{\max }$ of $412{ }^{\circ} \mathrm{C}$, while all the composite showed a similar $\mathrm{T}_{\max }$ of $405{ }^{\circ} \mathrm{C}$. The composites of the MDDG showed a slight increase in the decomposition temperature. This is due to the formation of a surface layer of epoxy POSS over the DDG particles.

\section{Surface Morphology}

The morphological study of the composites provides the information on the dispersion characteristics of fillers and their interaction with the matrix. The SEM images of the fracture surface of the composites are shown in Fig. 11. The composites showed coarse surfaces due to the irregular shape of the DDG. The $30 \mathrm{wt} \%$ DDG composite showed the existence of voids, indicating poor packing properties. These voids located at the interface of DDG and matrix can act as stress concentrators under load, leading to reduced flexural properties [5]. The 40 and $50 \mathrm{wt} \%$ DDG composites showed good packing of the DDG particles in the matrix. Furthermore, the surface modified DDG composites showed (Fig. 11d) improved wetting of the DDG particles by the resin. In general the hydrophilic biofillers are not compatible with the hydrophobic polymers and lead to poor interfacial adhesion [27]. The present study provides evidence for improved interfacial bonding between the DDG particles and matrix after using the epoxy 

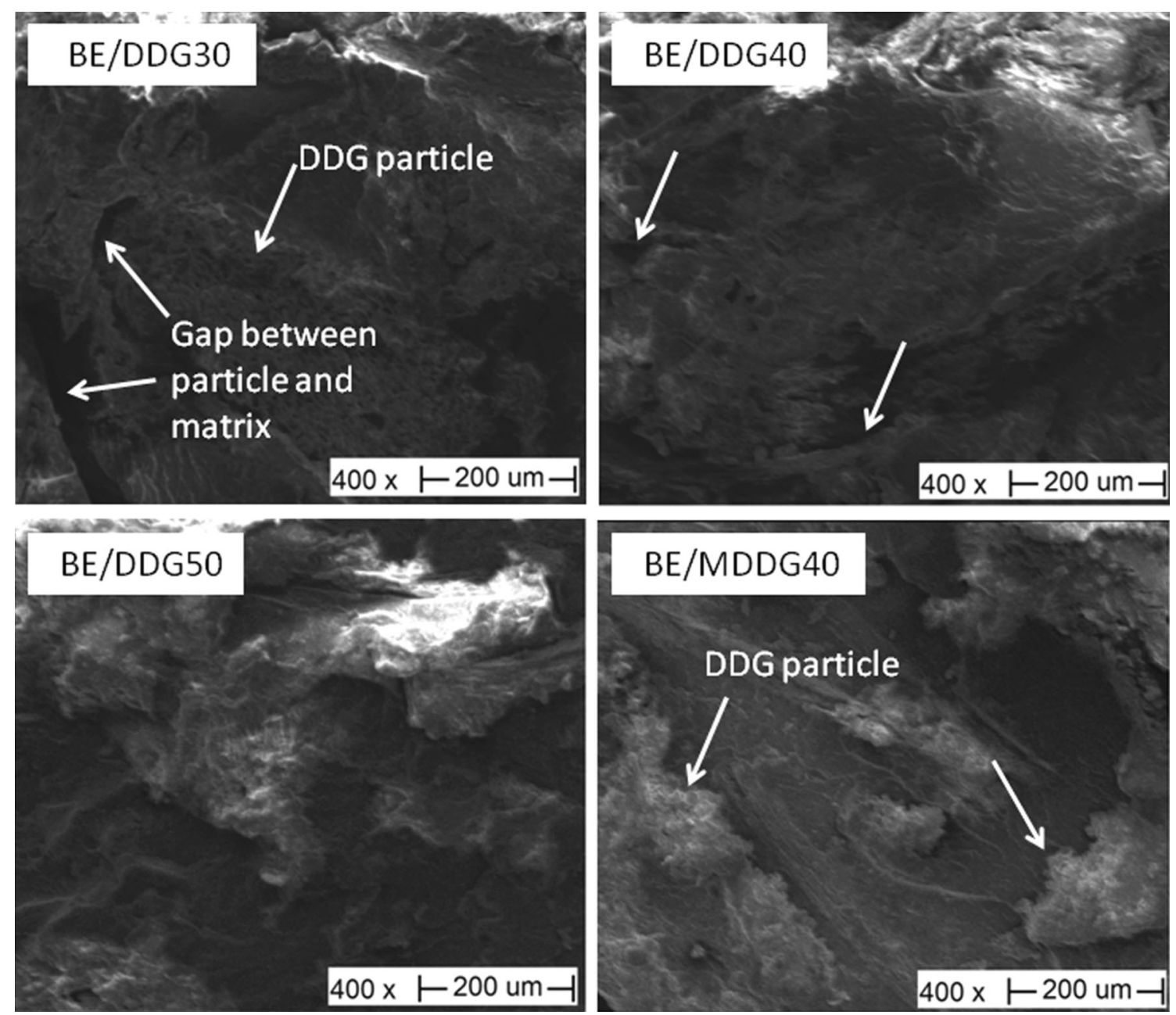

Fig. 11 SEM images showing the fracture surfaces of the DDG and MDDG filled composites

terminated siloxane as surface modifier/compatibilizer in this system.

\section{Conclusion}

The present work shows the successful fabrication of DDG filled biobased epoxy composites with mechanical properties similar to those of the neat polymer. The curing process was studied with DSC and modulated FTIR spectroscopy. The incorporation of the DDG and surface-modified DDG particles enhanced the curing of the resin as evident from the DSC and FTIR study. The optimum mechanical properties were obtained in the $40 \mathrm{wt} \%$ DDG filled composite, which had a modulus similar to that of the neat epoxy with limited reduction in strength. The mechanical properties were further improved by using epoxy terminated siloxane as a compatibilizer. The flexural properties were found to be better than those of the neat polymer. Similarly, a $12 \%$ increment was observed in the storage modulus. The morphological study also supports the observed mechanical and dynamic properties. The compact nature and good packing properties of the 40 and $50 \mathrm{wt} \%$ composites were evident from the SEM images. The surface modification of the DDG particles enhanced the adhesion between the DDG particles and the resin. This study shows the great potential of fabricating green composites from biobased epoxy and the low-cost DDG with good mechanical properties. This will expand the economic value of DDG from its current applications.

Acknowledgments The authors gratefully acknowledge the financial support from (1) the Ontario Ministry of Agriculture, Food, and Rural Affairs (OMAFRA)-New Directions Research Program (Project \# 050155) and (2) OMAFRA-University of Guelph Bioeconomy-Industrial Uses Theme (Project \# 200283). Authors also acknowledge Arkema, USA and GreenField Ethanol Inc., Chatham, Canada for providing ESO and DDGS samples respectively for this research. 
Open Access This article is distributed under the terms of the Creative Commons Attribution 4.0 International License (http://crea tivecommons.org/licenses/by/4.0/), which permits unrestricted use, distribution, and reproduction in any medium, provided you give appropriate credit to the original author(s) and the source, provide a link to the Creative Commons license, and indicate if changes were made.

\section{References}

1. "Global Ethanol Production", Alternative Fuels Data Center (AFDC) of the U.S. Department of Energy, http://www.afdc. energy.gov/data/. Accessed 1 Mar 2015

2. Wu Q, Mohanty AK (2007) J Biobased Mater Bioenergy 1:257

3. Tatara RA, Suraparaju S, Rosentrater KA (2007) J Polym Environ 15:89

4. Cheesbrough V, Rosentrater KA, Visser J (2008) J Polym Environ 16:40

5. Li Y, Sun XS (2011) J Appl Poly Sci 121:589

6. Renewable Fuels Association. http://www.ethanolrfa.org. Accessed 1 June 2012

7. Xu W, Reddy N, Yang Y (2009) Carbohydr Polym 76:521

8. Wang Y, Tilley M, Bean S, Sun XS, Wang D (2009) J Agric Food Chem 57:8366

9. Zarrinbakhsh N, Misra M, Mohanty AK (2011) Macromol Mater Eng 296:1035
10. Julson JL, Subbarao G, Stokke DD, Gieselman HH (2004) J Appl Polym Sci 93:2484

11. Schilling CH, Karpovich DS, Tomasik P (2009) J Biobased Mater Bioenergy 3:408

12. Miyagawa H, Misra M, Drzal LT (2005) Polym Eng Sci 45:487

13. Miyagawa H, Misra M, Drzal LT, Mohanty AK (2005) J Polym Environ 13:87

14. Miyagawa H, Mohanty AK, Misra M, Drzal LT (2004) Macromol Mater Eng 289:629

15. Shukla R, Cheryan M (2001) Ind Crop Prod 13:171

16. Parris N, Dickey LC (2003) J Agric Food Chem 51:3892

17. Zarrinbakhsh N, Mohanty AK, Misra M (2013) Biomass Bioenergy 55:251

18. Teo JKH, Teo KC, Pan B, Xiao Y, Lu X (2007) Polymer 48:5671

19. Lee L-H, Chen W-C (2005) Polymer 46:2163

20. Cherdoud-Chihani A, Mouzali M, Abadie MJM (1998) J Appl Polym Sci 69:1167

21. Silverstein RM, Webster FX (1997) Spectrometeric identification of organic compounds, 6th edn. Wiley, Canada

22. Clementson CL, Ileleji KE (2012) Bioresour Technol 107:213

23. Rosentrater KA, Otieno AW (2006) J Polym Environ 14:335

24. Lu J, Askeland P, Drzal LT (2008) Polymer 49:1285

25. Pfister DP, Larock RC (2010) Compos Part A Appl Sci Manufact 41:1279

26. Sahoo S, Misra M (2011) Compos Part A Appl Sci Manufact 42:1710

27. Zhang J, Jiang L, Zhu L (2006) Biomacromolecules 7:1551 